\title{
Nongalenic arteriovenous fistulas: history of treatment and technology
}

\author{
Kristen Upchurch, M.D., Lei Feng, M.D., Ph.D., Gary R. Duckwiler, M.D., \\ John G. Frazee, M.D., Neil A. Martin, M.D., ANd Fernando Viñuela, M.D. \\ Division of Neurosurgery, Department of Surgery; Division of Interventional Neuroradiology, \\ Department of Radiological Sciences; and Division of Interventional Neuroradiology, Department of \\ Radiological Sciences, University of California Los Angeles Medical Center and David Geffen School \\ of Medicine at the University of California Los Angeles; and Department of Diagnostic Imaging, \\ Kaiser Permanente Medical Center, Los Angeles, California
}

\begin{abstract}
$\checkmark$ Nongalenic cerebral arteriovenous fistulas (AVFs) are uncommon, high-flow vascular lesions first treated by Walter Dandy and his colleagues by using open surgery with ligation of the feeding artery. Due to advances in endovascular technology over the past four decades that make possible the control of high flow in AVFs, treatment has evolved from the sole option of surgery to include the alternative or adjunct option of endovascular embolization. The authors of this review discuss the history of nongalenic AVF treatment, including techniques of both surgery and interventional neuroradiology and the technological developments underlying them.
\end{abstract}

\section{KEY WORDS • nongalenic arteriovenous fistula • embolization • endovascular therapy • history of neurosurgery}

A RTERIOVENOUS fistulas consist of a direct high-flow connection between an artery and a vein without an intervening nidus. ${ }^{1,8,21,36}$ Arteriovenous fistulas termed "nongalenic" are uncommon vascular malformations that do not involve a persistent embryonic median prosencephalic vein; they are called nongalenic because they are a class of lesion separate from so-called vein of Galen aneurysms or malformations. In this article we first describe the historical classification, anatomy, and clinical features of nongalenic AVFs as background and then we focus on the history of their treatment. This history is necessarily recent, given the emphasis on innovations in endovascular technology that have improved the ability to diagnose nongalenic AVFs and expanded options for their treatment.

The treatment of nongalenic AVFs has changed dramatically during the past several decades due to technical advances. From the early days of neurosurgery to the 1960s, nongalenic AVFs were treated only with open surgery. As new technology has improved the potential for endovascular control over these lesions' high flow, embolization performed by interventional neuroradiologists has become an

Abbreviations used in this paper: $\mathrm{AVF}=$ arteriovenous fistula; $\mathrm{AVM}=$ arteriovenous malformation; ICA = internal carotid artery; $\mathrm{MCA}=$ middle cerebral artery; $\mathrm{MR}=$ magnetic resonance; $\mathrm{UCLA}=$ University of California Los Angeles; UWO = University of Western Ontario. accepted treatment, either alone or combined with surgery or stereotactic radiosurgery. The history of treatment for nongalenic cerebral AVFs is discussed in this paper in terms of technological progress-from the sole option of open surgery in the early era of treatment to the present-day adjunct and alternative option of endovascular therapy.

\section{Historical Classification}

Due to their rarity and to the difficulty in accurately defining their angioarchitecture in the preangiography era, nongalenic AVFs typically were not recognized as a distinct category of vascular lesion in historical classifications. Nongalenic AVFs were grouped by Walter Dandy ${ }^{8}$ in his 1928 series with the general class of vascular malformations that he called "arteriovenous aneurysms." 26 Later, in a classic 1945 review of intracranial vascular lesions, Noran ${ }^{26}$ distinguished the categories of "cerebral varix" and "arteriovenous angioma," with no exact fit for nongalenic AVFs in his extensive classification system. When McCormick ${ }^{24}$ published his streamlined classification of vascular malformations in 1966, he proposed the separate categories of "varix" and "arteriovenous malformation (angioma)" without explicitly describing nongalenic AVFs, which are neither simply varices nor classic AVMs. In the past, given their infrequency and the absence of a specific classification category, nongalenic AVFs were often grouped with AVMs in clinical series. As will be described, the capacity of modern angiog- 
raphy to define angioarchitecture precisely has allowed the distinction of nongalenic AVFs from AVMs, adding a category to the classification of cerebrovascular lesions and thereby improving the diagnosis and treatment of these lesions.

\section{Defining Features}

\section{Infrequency of Nongalenic AVFs}

Nongalenic AVFs are rare lesions. They arise sporadically both as isolated phenomena and in congenital, nonhereditary Wyburn-Mason syndrome; they also occur in inherited disorders such as the Rendu-Osler-Weber syndrome. ${ }^{6,27,30,35}$ The infrequency of nongalenic AVFs can best be assessed in the context of more common AVMs by considering two single-institution experiences recorded during 10 -year periods. At one tertiary care institution, five (1.6\%) of 320 AVMs treated in a 10-year period were found to be nongalenic $\mathrm{AVFs},{ }^{15}$ at another tertiary care center, in the same length of time, 12 (4.8\%) of 251 cerebrovascular malformation cases (not including dura-based lesions) were diagnosed as nongalenic AVFs. ${ }^{36}$ Given an AVM incidence of approximately 1 per 100,000 per year in unselected populations, the rarity of nongalenic AVFs is clear.

\section{Anatomy of Nongalenic AVFs}

Nongalenic AVFs can be single or multiple, with a higher probability of multiple lesions occurring in patients with inherited syndromes. ${ }^{6}$ The anatomical and physiological hallmark of the nongalenic AVF is the direct emptying of one or more feeding arteries into a large varix that has very high flow. This associated varix is a venous ectasia distal to the fistula that most likely develops due to the varix's high flow and often has mural calcification..$^{21,36-38,41}$ Nongalenic AVFs are always associated with such a varix and are sometimes associated with other vascular abnormalities such as AVMs or aneurysms. Such aneurysms typically are located at a bifurcation where a minor vessel branches off a major feeding artery immediately proximal to the fistula. ${ }^{36}$

The varix of a nongalenic AVF is typically extraparenchymal, with the fistula itself in a superficial cortical location and often obscured by the varix..$^{21,37}$ The location of the varix correlates with the arterial supply of the AVF, with frontal and medial parietal varices fed by the anterior cerebral artery, temporal and parietal convexity varices associated with the MCA, and occipital varices supplied by the posterior cerebral artery (Fig. 1). ${ }^{21}$ More posteriorly located lesions are sometimes supplied by branches of the basilar artery. ${ }^{21,36}$ The route of venous drainage depends on the location of the nongalenic AVF, with most interhemispheric and convexity varices draining into the superior sagittal sinus and many temporal and occipital AVFs reported as draining into both the superior sagittal and transverse sinuses. ${ }^{21}$

\section{Clinical Aspects}

\section{Clinical Presentation}

The size, angioarchitecture, and high-flow state of nongalenic AVFs, as well as the age of the patient, dictate their clinical presentation, which takes different forms depending
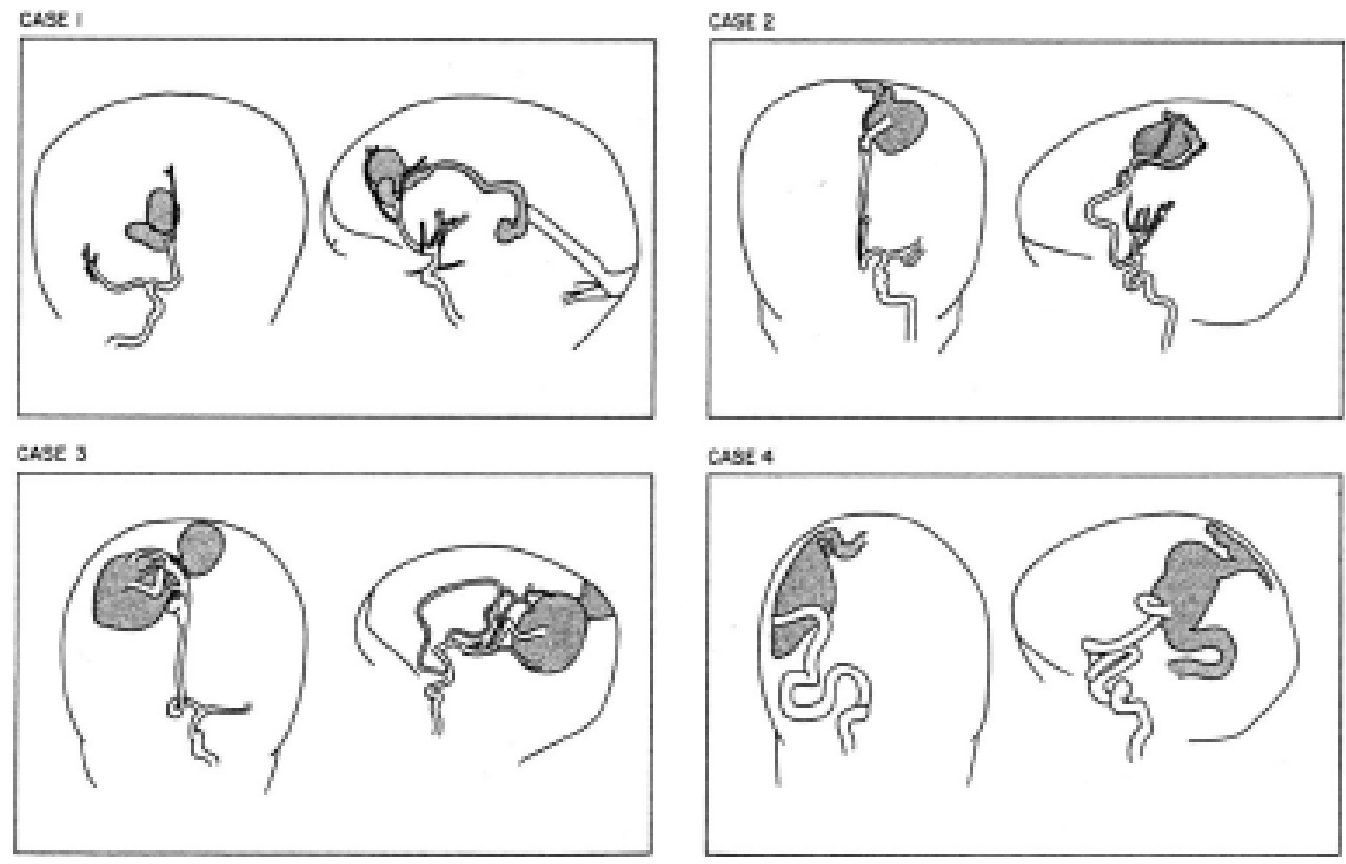

FIG. 1. Schematics depicting the gross angioarchitecture of four cases of nongalenic AVFs from the 1992 UWOUCLA series, demonstrating that frontal and medial parietal varices are typically fed by the anterior cerebral artery (Cases 1-3), whereas parietal convexity varices (Case 4) and temporal varices (not shown) are supplied by the MCA. (Artists: Steve Lownie, M.D., and George Moogk.) Figure reprinted with permission of both Dr. Lownie and Lippincott, Williams, \& Wilkins: Lownie SP, Duckwiler GR, Fox AJ, Drake CG: Endovascular therapy of nongalenic cerebral arteriovenous fistulas, in Viñuela F, Halbach VV, Dion JE (eds): Interventional Neuroradiology: Endovascular Therapy of the Central Nervous System. New York, Raven Press Ltd, copyright 1992. 

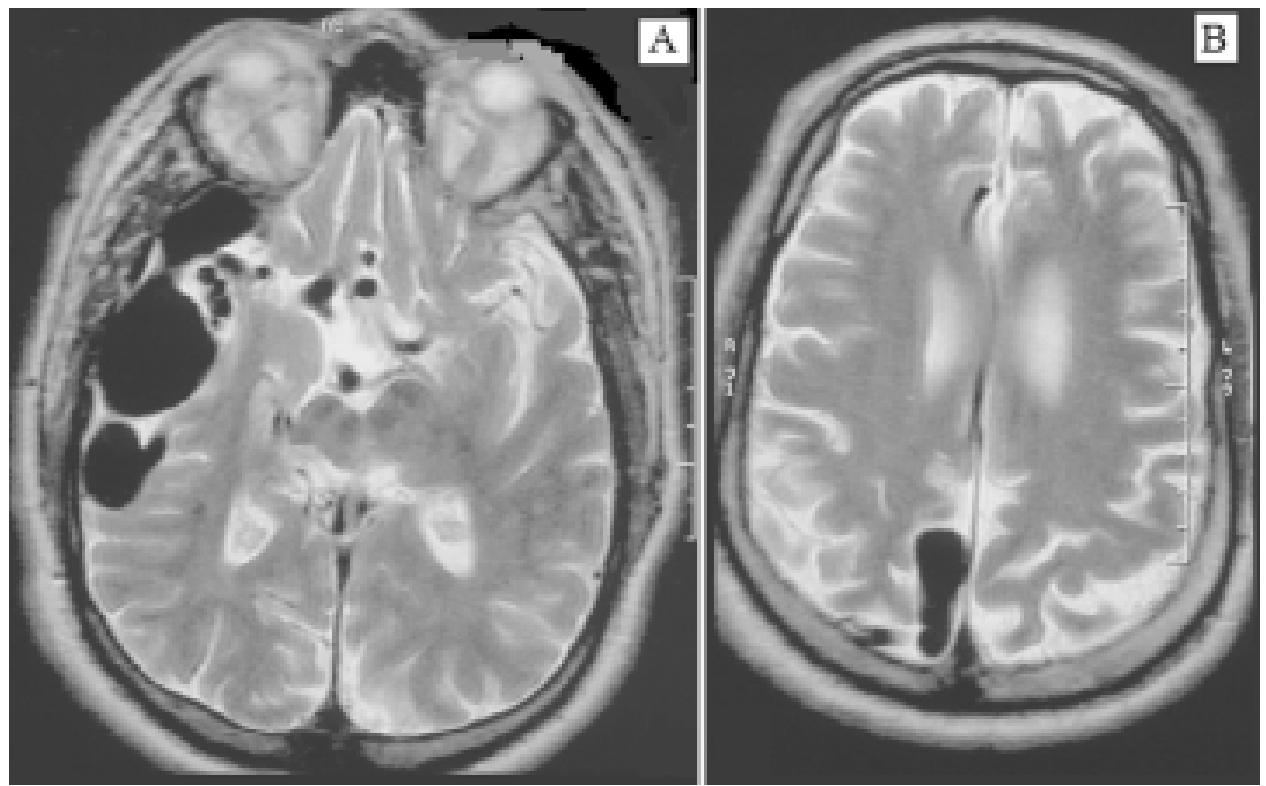

FIG. 2. Pretreatment $\mathrm{T}_{2}$-weighted $\mathrm{MR}$ images, axial views, obtained in a patient recently treated with endovascular embolization at UCLA, showing large flow voids, consistent with the diagnosis of right temporal nongalenic AVF (A) and right medial parietal nongalenic AVF (B).

on the presence of mass effect, arterial steal, or venous hypertension. ${ }^{36,38}$ Although commonly congenital, nongalenic AVFs typically present after the neonatal period. ${ }^{21}$ Those that are diagnosed in the neonatal period are usually found secondary to congestive heart failure, similar to vein of Galen malformations. After the neonatal period, infants with nongalenic AVFs present with increasing head circumference or focal neurological deficit. Adolescents and adults who have nongalenic AVFs present with headache, seizures, and focal neurological deficit. ${ }^{21,35,36,38}$ Acute presentation due to subarachnoid or intracerebral hemorrhage is much less common but does occur. ${ }^{21,36,38}$

Asymptomatic adults with nongalenic AVFs have rarely been described. In a 1987 case series at the UWO, all of the adults with high-flow nongalenic AVFs associated with giant intracranial varices were symptomatic due to neurological and/or cardiac disease. ${ }^{38}$ All patients in a 1989 series at the University of California San Francisco and all adults with these cerebral lesions in a 1993 Mayo Clinic series were symptomatic. ${ }^{15,36}$ Described in a case report published in 2004, an adult patient with Rendu-Osler-Weber syndrome came to medical attention as a result of neurological symptoms due to a spinal AVF, underwent an examination that revealed a field cut, and was found also to have a cerebral AVF. ${ }^{27}$ One adult with nongalenic AVFs described in a UWO-UCLA 1992 series as both asymptomatic and without neurological deficits came to medical attention because of a vascular abnormality: this 25-year-old woman presented with a massive cirsoid aneurysm (AVF) of the scalp and was found to have two ipsilateral nongalenic cerebral AVFs. ${ }^{21}$ A truly asymptomatic patient who recently underwent successful endovascular treatment at UCLA was found to harbor two large, discrete nongalenic cerebral AVFs, one right temporal and the other right medial parietal (Figs. 2-6). These lesions were incidentally discovered when the patient underwent cerebral imaging for staging after melanoma diagnosis.

\section{Diagnosis of Nongalenic AVFs}

In Dandy's era, the diagnosis of a nongalenic cerebral AVF was based on clinical symptoms and signs (for exam-

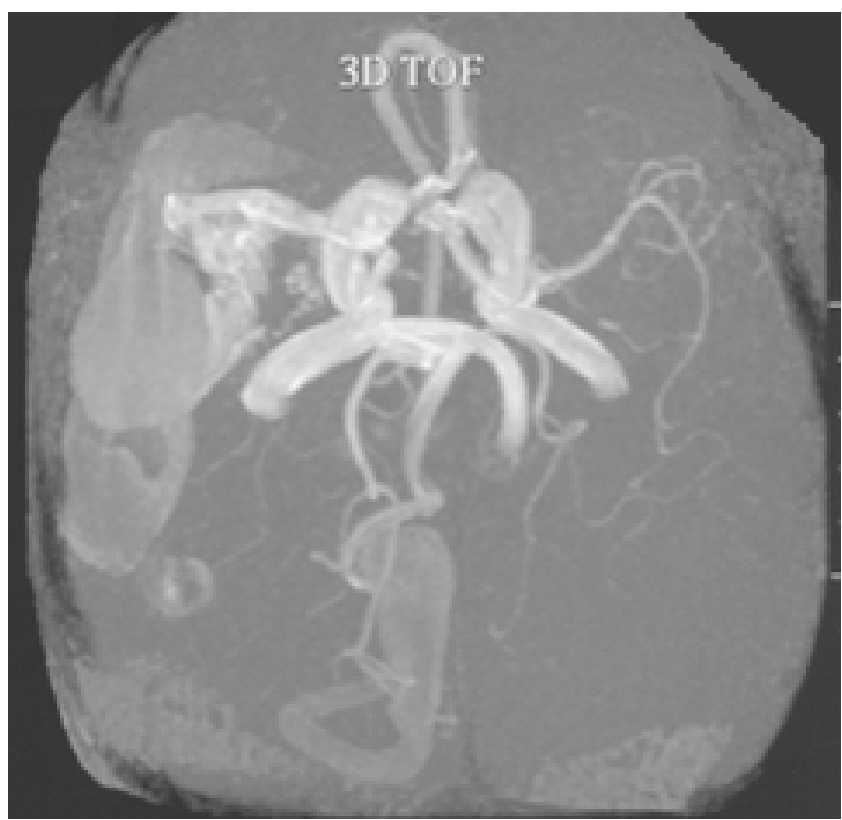

FIG. 3. Magnetic resonance angiography image obtained in the same patient as in Fig. 2, demonstrating dilated feeding arteries without a nidus, consistent with the diagnosis of two discrete nongalenic AVFs, each associated with a giant varix. TOF = time of flight. 
K. Upchurch, et al.

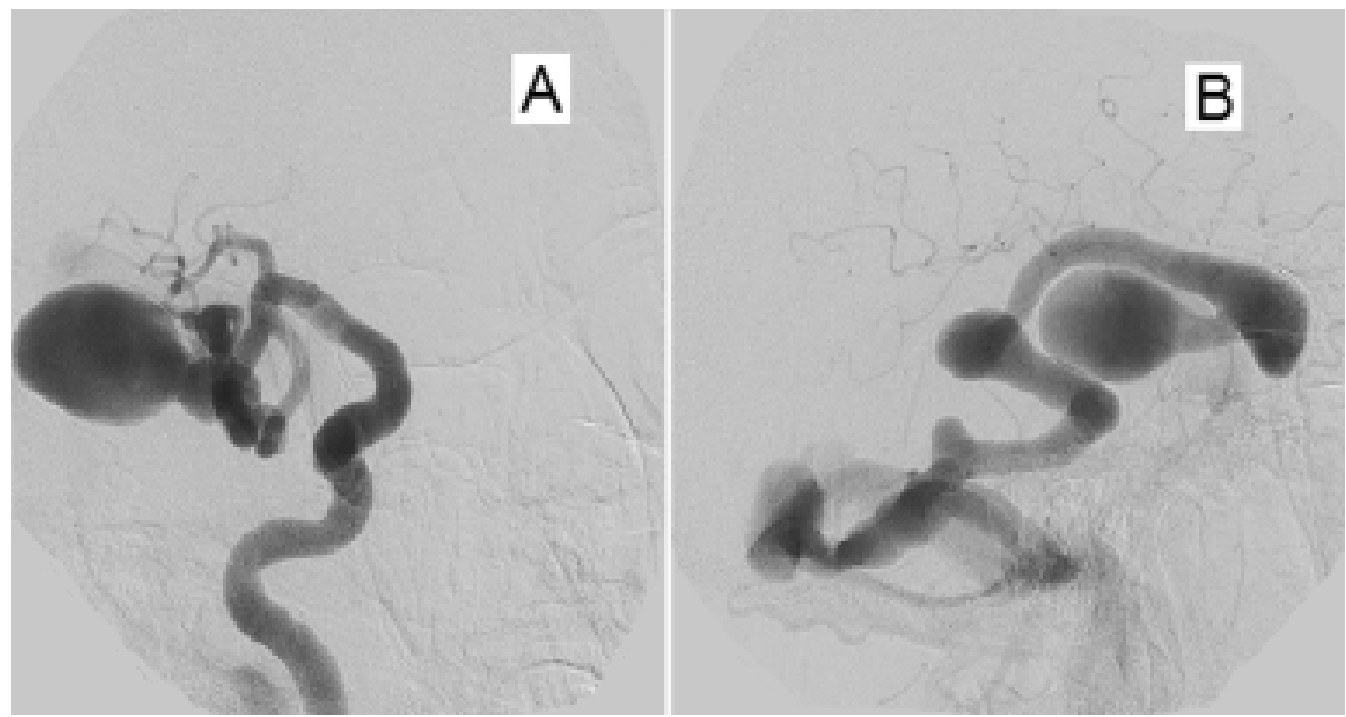

FIG. 4. Diagnostic pretreatment angiograms from the same patient as in Fig. 2. The anterior oblique view of the right ICA injection (A) demonstrates the right temporal AVF's feeding arteries off the right MCA. The lateral view of the right ICA injection (B) shows the venous drainage of the right temporal AVF into the right superficial middle cerebral vein, vein of Labbé, and transverse sinus.

ple, auscultation of bruits), substantiated by pneumoencephalography, and then confirmed by direct visualization at craniotomy. ${ }^{8}$ Currently, initial computerized tomography and MR imaging studies are routinely obtained, followed by digital subtraction angiography, the diagnostic gold standard. ${ }^{38}$ In a 1993 Mayo Clinic series, the following three angiographic criteria were suggested for the diagnosis of cerebral AVFs: 1) rapid circulation time due to high-velocity flow; 2) enlarged feeding arteries; and 3) direct filling of a large varix (described as "jet phenomenon" on MR angiography).$^{36}$ Currently, precise delineation of lesion angioarchitecture using biplanar and three-dimensional rotational selective and superselective angiography permits accurate diagnosis of nongalenic AVFs and also serves as a guide for planning treatment. ${ }^{16,38,39}$ Overlapping arterial and venous collateral vessels may make visualization of an AVF diffi- cult during routine angiographic injections. It is crucial to use superselective angiography to distinguish nongalenic cerebral AVFs from AVMs, given that the treatment strategies for these lesions differ. ${ }^{36,38}$

\section{History of Surgical Treatment: Dandy and Drake}

The goal of nongalenic AVF treatment is obliteration of the fistula via occlusion of its arterial supply without premature occlusion of its venous drainage..$^{5,17,35,37}$ This objective can be achieved using surgical or endovascular therapy, separately or in combination. ${ }^{3,21,36,38}$ Historically, nongalenic AVFs were treated at craniotomy by occluding feeding arteries as close as possible to the site of the fistula, initially by ligation and later by clipping. ${ }^{5,8,11} \mathrm{~A}$ review of cases of nongalenic cerebral AVF reported between 1928 and the

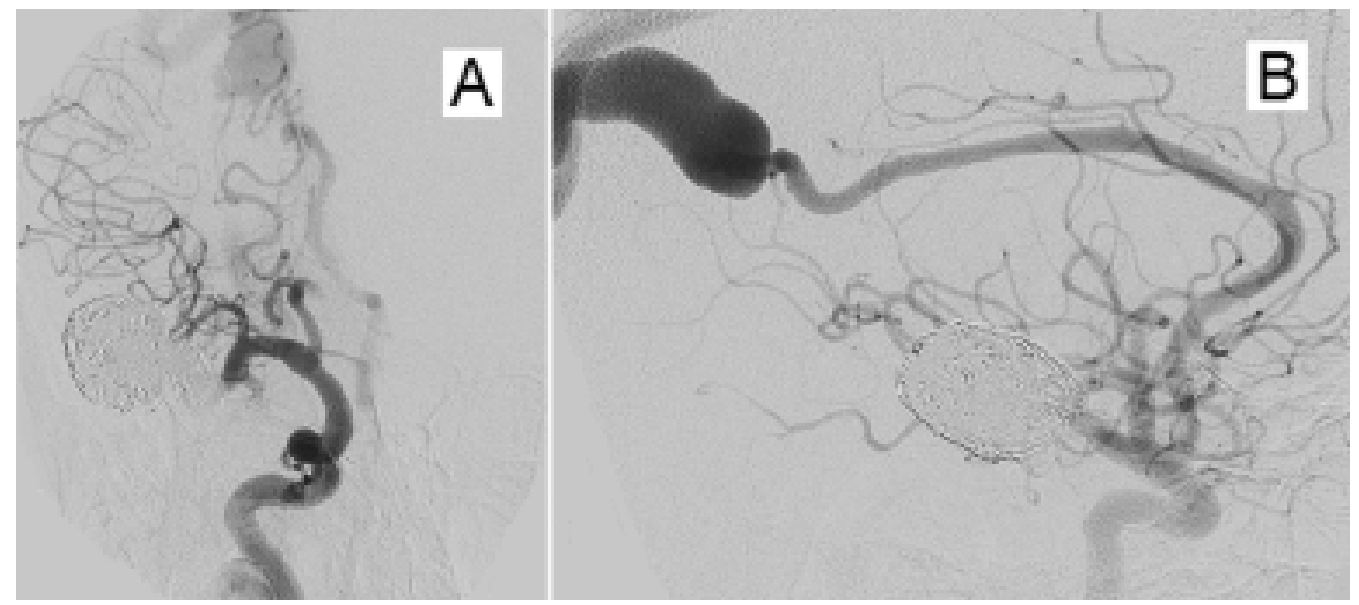

FIG. 5. Midtreatment angiograms of the same patient as in Fig. 2. In the anteroposterior view of the right ICA injection after embolization of the right temporal AVF, the right medial parietal AVF is now visualized (A). The lateral view of the left ICA injection demonstrates the venous drainage of the right medial parietal AVF (B). 


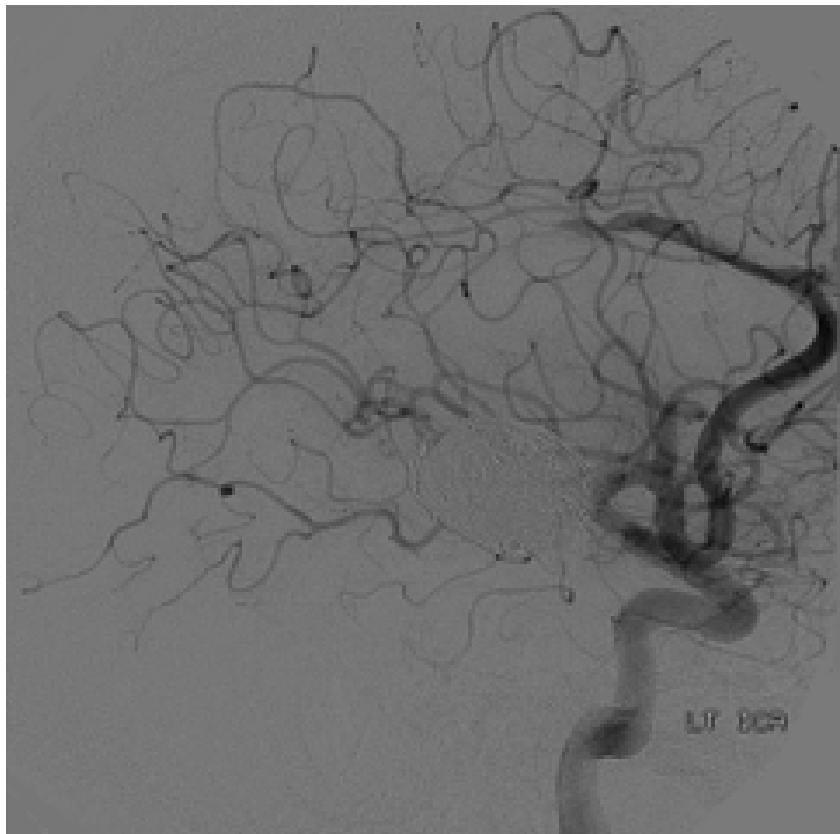

FIG. 6. Posttreatment angiogram of the same patient as in Fig. 2, demonstrating a lateral view of the left ICA injection after embolization of the right medial parietal AVF.

present reveals that the original role of surgery was augmented over time by complementary or alternative endovascular treatment, due to technological progress in interventional neuroradiology.

\section{Surgical Treatment by Dandy}

Open surgery with ligation was at first the only treatment option for nongalenic AVFs. In his 1928 series of "arteriovenous aneurysms of the brain," Dandy ${ }^{8}$ reported the surgical treatment of a lesion that he described as a "pure arteriovenous fistula," that is, a nongalenic AVF supplied by a single feeding artery off the right MCA, which connected directly to an enlarged venous trunk (Fig. 7). At the initial operation, Dandy performed a craniotomy, observed the massive venous drainage of the lesion on the surface of the right temporal and frontal lobes, and then closed. He wrote, "Since any attempt to treat the aneurysm surgically appeared to involve a risk greater than my co-workers and I were justified in assuming, the dura was closed and the bone flap was replaced." At reoperation, the feeding artery was ligated and the varix was then observed to collapse immediately (Fig. 8). Although the 52-year-old patient's seizure disorder was cured by the surgical treatment of his AVF, postoperatively he had a new permanent deficit of mild left hemiparesis. Dandy reached a cautionary conclusion in summarizing his clinical experience with this lesion and other types of cerebral arteriovenous aneurysms. He wrote, "Radical ligations or extirpations alone are curative, but are exceedingly dangerous to life and function and are indicated in the minority of cases. . .." Dandy's surgical treatment of these cerebrovascular lesions was limited by the technology available in his time (Fig. 9 left).

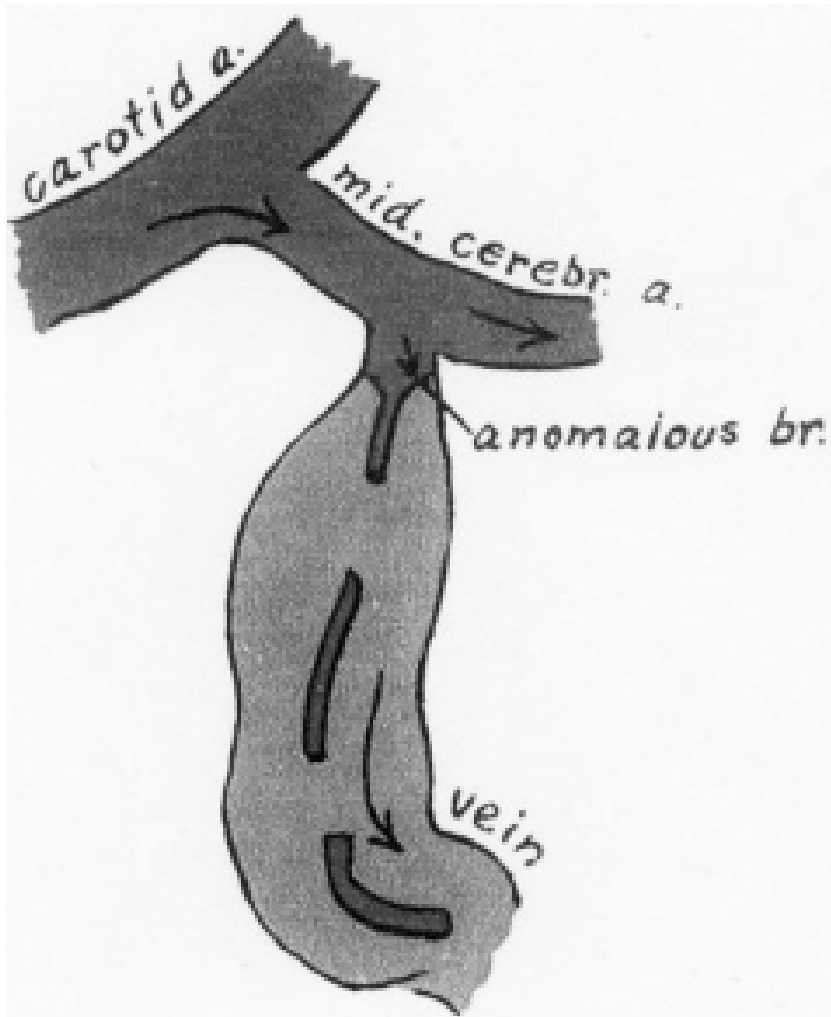

FIG. 7. Sketch by Dandy of a nongalenic AVF that he treated surgically, as described in his 1928 series. The lesion was supplied by a single feeding artery off the right MCA that emptied directly into a varix. a. $=$ artery; br. $=$ branch; mid. cerebr. $=$ middle cerebral . (Arch Surg 17: 196, copyright 1928, American Medical Association. All rights reserved; reprinted with permission.)

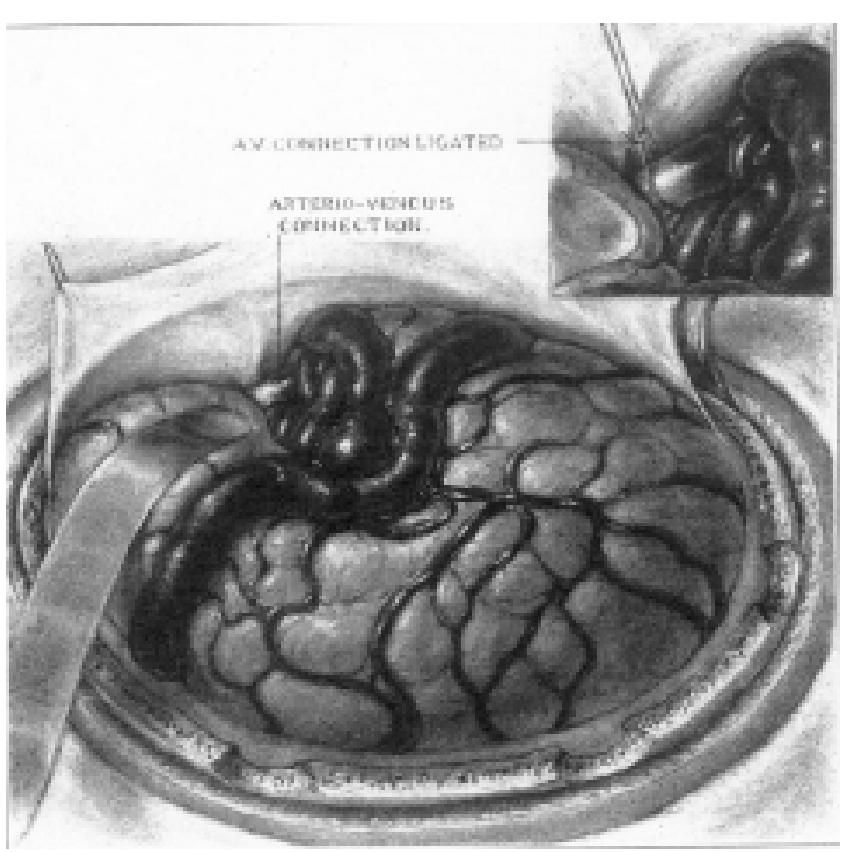

FIG. 8. Dandy's illustration of the same nongalenic AVF shown in Fig. 7, observed in situ at craniotomy, demonstrating ligation of the feeding artery. (Arch Surg 17: 196, copyright 1928, American Medical Association. All rights reserved; reprinted with permission.) 


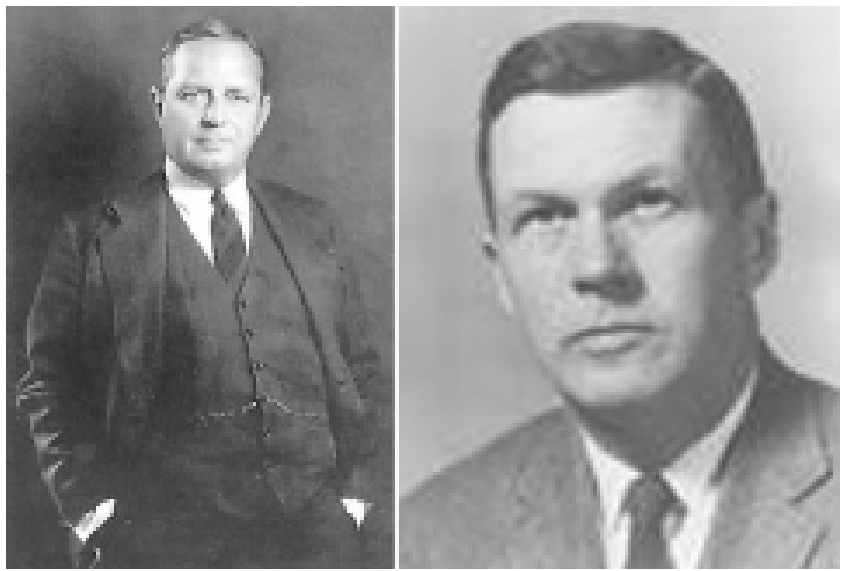

FIG. 9. Photographs of W. E. Dandy, M.D. (left) and C. G. Drake, M.D. (right). (Photographs courtesy of the AANS Archives.)

\section{Surgical Treatment by Drake}

In the 1960s and 1970s, technological innovations led to intraoperative and transfemoral embolization as a new strategy for treating cerebrovascular lesions. Yet open surgery with clip occlusion of feeding arteries remained the treatment option of choice for most cerebral AVMs and invariably also for nongalenic AVFs in the 1970s. In his 1979 series of 166 patients with cerebral AVMs, Charles Drake (Fig. 9 right) included two cases of nongalenic AVFs associated with huge varices. Although five AVMs in this series were treated with flow-directed or direct selective plastic bead embolization, this type of procedure was not an option for nongalenic AVFs, given the dangers posed by the AVFs' high flow and associated massive varix. The two patients with nongalenic AVFs in Drake's series underwent surgical clip occlusion of feeding arteries. This was a success in one patient, but the other patient died 24 hours after the operation due to intracerebral hemorrhage attributed to hemodynamic alteration. In this case of death resulting from hemorrhage, the venous outlet of the AVF was not surgically occluded during the operation, and later autopsy confirmed the patency of the varix. As in the case of Dandy's patient, the varix collapsed on itself after Drake occluded the solitary large feeding artery of the AVF (in this case with a single clip). Drake ${ }^{11}$ hypothesized that the cause of hemorrhage was rupture of a deep normal artery.

Surgical treatment of nongalenic AVFs poses some disadvantages particular to the lesions' anatomy. For example, at craniotomy, visualization and access to the fistula itself are often hindered by the presence of a massive associated varix. ${ }^{8,17,25}$ Endovascular therapy avoids this problem and is now a frequently selected treatment option for nongalenic AVFs. The modern history of the innovations underlying the optimization of endovascular treatment for nongalenic AVFs is discussed in the following section.

\section{History of Innovations Leading to Endovascular Treatment}

\section{Challenges of Endovascular Treatment}

Due to the high flow in these lesions, treatment of nongalenic AVFs always carries the danger of rapid hemodynamic alteration, also known as normal perfusion pressure breakthrough, which may result in cerebral injury and death. ${ }^{34,38,40}$ In addition, given their high flow and dilated venous drainage, the risk of inadvertently occluding the venous outflow of nongalenic AVFs has posed a particular challenge to treating these lesions with endovascular embolization. ${ }^{25,38}$ Currently, however, this particular anatomical characteristic of nongalenic AVFs- the associated dilated varix - has made the fistulas especially amenable to modern endovascular techniques, given that this venous outlet can be used in the endovascular approach.

Despite the anatomical differences between nongalenic AVFs and other cerebrovascular lesions, technical advances originally made in the endovascular treatment of intracranial AVMs and aneurysms have been directly applicable to the embolization of nongalenic AVFs. These innovations have included the optimization of embolic agents, the development of new types of catheters, and the use of preembolization superselective angiography.

\section{Embolic Agents: Historical Development From 1930 to the Modern Era}

Embolization materials have gradually improved since 1930, when Brooks inserted a piece of muscle into a patient's carotid artery to embolize a carotid-cavernous fistula..$^{32}$ The first materials used were muscle, Gelfoam, and solid plastic particles; later advancements included detachable balloons, rapidly polymerizing liquid agents, and detachable coils. In 1960, Luessenhop and Spence ${ }^{23}$ described the successful flow-directed embolization of a large left frontotemporal AVM by using solid particles (four spherical methyl methacrylate emboli) introduced into the surgically exposed left carotid artery. In 1974, Serbinenko reported his innovative use of detachable balloons to occlude cerebral vessels by percutaneously introducing balloon catheters into the vascular system and maneuvering them into the intracranial arteries. In the early 1980s, rapidly polymerizing cyanoacrylates were established as efficacious in both the intraoperative and transfemoral embolization of cerebral AVMs. ${ }^{7,10,41}$ In the 1990s, Guglielmi and coworkers $^{12-14}$ described their successful use of electrolytically detachable platinum coils and soft microcatheters to perform endovascular electrothrombosis of intracranial aneurysms (Fig. 10). On the basis of these innovations, vascular neurosurgeons and interventional neuroradiologists began to work together to combine open surgery with intraoperative and/or transfemoral embolization of nongalenic AVFs as well as AVMs. ${ }^{22,33,38,43}$

\section{Successes and Failures in Embolization of Nongalenic} AVFs

This technological progress improved the efficacy of endovascular embolization as treatment for cerebrovascular lesions in general and made possible its application to nongalenic AVFs. However, as in the history of any new technology, attempts to treat nongalenic AVFs with interventional neuroradiology were initially often unsuccessful. The specific causes of failure in individual cases were diverse: inability to control the fistula's high flow; 4,38 imprecise balloon placement too proximal to the fistula site ${ }^{15}$ development of new collateral feeding arteries after embolization; ${ }^{15}$ imprecise placement of platinum coils; and failure to occlude all feeding arteries, probably due to incomplete an- 


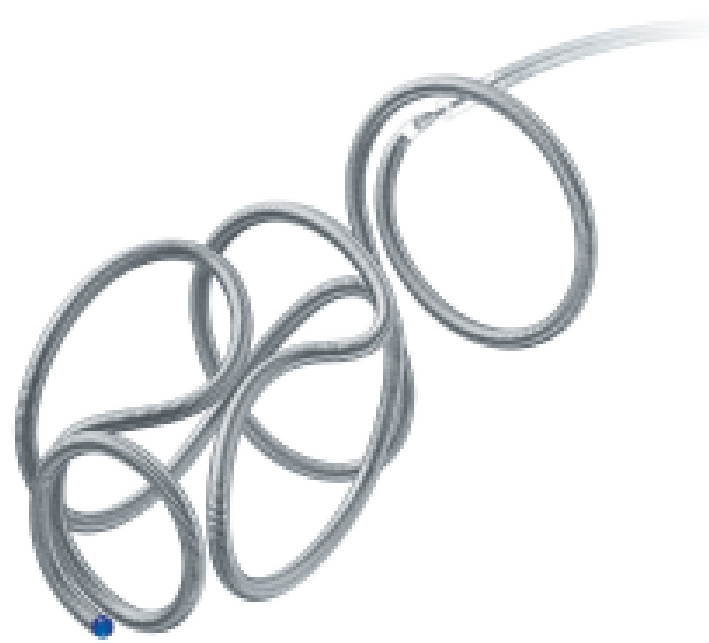

FIG. 10. Illustration of the most recent Guglielmi detachable coil (GDC 360), manufactured in 2004. (Schematic courtesy of Boston Scientific.)

giographic visualization of the lesion angioarchitecture. ${ }^{3}$ For some patients with nongalenic AVFs, combined endovascular and surgical approaches were planned in advance. Others whose endovascular embolization failed were subsequently advised to undergo craniotomy only after interventional neuroradiological techniques failed. ${ }^{3,35,36,38}$

\section{Superselective Angiography}

The root causes of past unsuccessful embolization of nongalenic AVFs have lain primarily in technological limitations, including the inability to visualize AVF angioarchitecture fully due to incomplete angiographic injections. In the past few decades, the development of pretreatment selective and superselective angiography has made possible the accurate delineation of lesion angioarchitecture is essential to planning successful lesion-specific treatment, whether endovascular, surgical, or both. ${ }^{16,20,38,39}$

Selective and superselective catheterization of cortical vessels was made feasible by the development of transvascular navigation techniques in the 1970s and 1980s. Of particular importance was the innovation of balloon catheters that can be maneuvered along the acute curves of cortical vessels without causing vascular injury., ${ }^{9,18,19,28,29,32,39}$ Due to these technical advances, present-day superselective angiography can produce detailed images of a cerebrovascular lesion's anatomy. This precise angioarchitectural map then can be used to determine the best endovascular approach, whether transarterial or transvenous, as Houdart ${ }^{16}$ demonstrated in his angioarchitecture-based classification of intracranial vascular lesions (Fig. 11). Importantly, superselective angiography provides both anatomical and functional information. It delineates the feeding arteries and the venous drainage of the nongalenic $\mathrm{AVF}$ and also permits estimation of the arteriovenous transit time of an arteriovenous shunt. ${ }^{39}$ This estimated transit time is important in calculating the correct rate of cyanoacrylate injection to occlude the fistula safely. ${ }^{38,39,41}$

\section{Conclusions}

The impact of the technical advances described in this

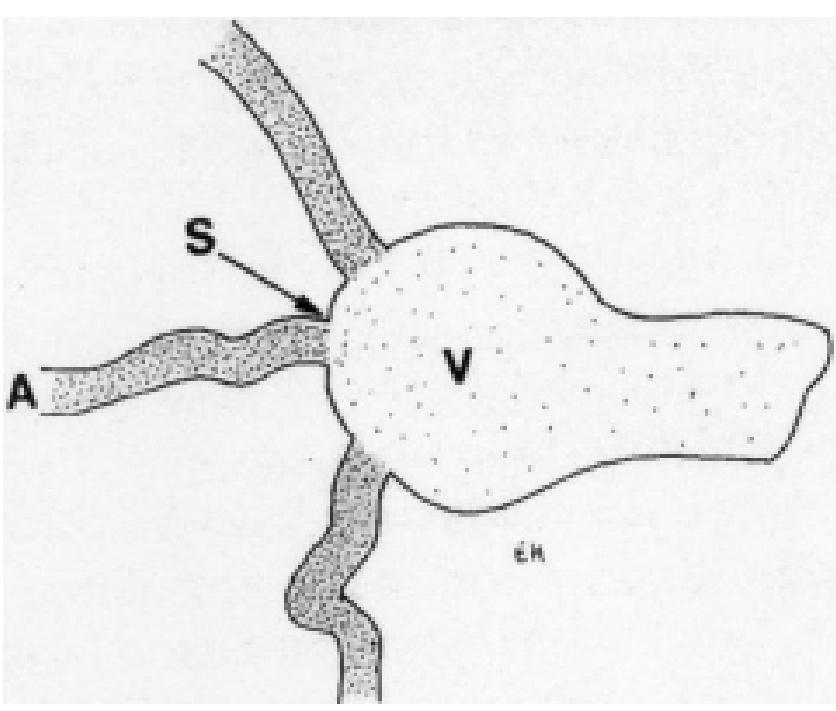

FIG. 11. Sketch by Houdart of an AVF for his angioarchitectural classification, with "AVF" defined as a fistula with no more than three feeding arteries (A) forming a direct shunt (S) to the venous compartment (V). Houdart E, Gobin YP, Casasco A, Aymard A, Herbreteau D, Merland JJ: A proposed angiographic classification of intracranial arteriovenous fistulae and malformations. Neuroradiology 35:382, Figure 2a, copyright 1993 . Figure reprinted with kind permission of Springer Science and Business Media.

paper is revealed by the improved diagnosis and successful endovascular treatment of nongalenic cerebral AVFs. From 1928 to the present, more than 47 adults and children with nongalenic AVFs have been described, either in individual case reports or in case series, with open surgery the only possible treatment in early cases. ${ }^{2-6,8,11,15,17,21,25,27,31,35-38,40,42}$ In the modern era, there remain certain nongalenic AVFs that are best approached in open surgery for anatomical reasons. Also, practitioners today sometimes still hesitate to treat nongalenic cerebral AVFs with endovascular embolization due to the danger of embolic material migrating into the lungs, cortical veins, or dural venous sinuses because of the lesions' high flow. ${ }^{27,38}$ However, the technological progress in interventional neuroradiology made over the past four decades currently supports many different strategies to reduce flow during endovascular treatment and to avoid this risk. Due to such technical innovations, the success rate of interventional neuroradiological treatment has improved dramatically, and it is now the optimal treatment approach for many nongalenic AVFs. On this basis, endovascular embolization is currently established as an important alternative to open surgery for the treatment of nongalenic AVFs.

\section{Disclosure}

Dr. Viñuela is a consultant for Boston Scientific, Inc./Target, which manufactures Guglielmi detachable coils.

\section{References}

1. Al-Shahi R, Warlow C: A systematic review of the frequency and prognosis of arteriovenous malformations of the brain in adults. Brain 124:1900-1926, 2001

2. Aoki N, Sakai T, Oikawa A: Intracranial arteriovenous fistula 
manifesting as progressive neurological deterioration in an infant: case report. Neurosurgery 28:619-623, 1991

3. Barnwell SL, Ciricillo SF, Halbach VV, Edwards MS, Cogen PH: Intracerebral arteriovenous fistulas associated with intraparenchymal varix in childhood: case reports. Neurosurgery 26:122-125, 1990

4. Bendok BR, Getch CC, Frederiksen J, Batjer HH: Resection of a large arteriovenous fistula of the brain using low-flow deep hypothermic cardiopulmonary bypass: technical case report. Neurosurgery 44:888-891, 1999

5. Carrillo R, Carreira LM, Prada J, Rosas C, Egas G: Giant aneurysm arising from a single arteriovenous fistula in a child. Case report. J Neurosurg 60:1085-1088, 1984

6. Coubes P, Humbertclaude V, Rodesch G, Lasjaunias P, Echenne B, Frerebeau P: Total endovascular occlusion of a giant direct arteriovenous fistula in the posterior fossa in a case of RenduOsler-Weber disease. Childs Nerv Syst 12:785-788, 1996

7. Cromwell LD, Harris AB: Treatment of cerebral arteriovenous malformations: a combined neurosurgical and neuroradiological approach. J Neurosurg 52:705-708, 1980

8. Dandy WE: Arteriovenous aneurysm of the brain. Arch Surg 17:190-243, 1928

9. Debrun G, Lacour P, Caron J: Detachable balloons and calibrated-leak balloon techniques in the treatment of cerebral vascular lesions. J Neurosurg 49:635649, 1978

10. Debrun G, Viñuela F, Fox A, Drake CG: Embolization of cerebral arteriovenous malformations with bucrylate. J Neurosurg 56:615-627, 1982

11. Drake CG: Cerebral arteriovenous malformations: considerations for and experience with surgical treatment in 166 cases. Clin Neurosurg 26:145-208, 1979

12. Guglielmi G, Viñuela F, Dion J, Duckwiler G: Electrothrombosis of saccular aneurysms via endovascular approach. Part 2: preliminary clinical experience. J Neurosurg 75:8-14, 1991

13. Guglielmi G, Viñuela F, Duckwiler G, Dion J, Lylyk P, Berenstein A, et al: Endovascular treatment of posterior circulation aneurysms by electrothrombosis using electrically detachable coils. J Neurosurg 77:515-524, 1992

14. Guglielmi G, Viñuela F, Sepetka I, Macellari V: Electrothrombosis of saccular aneurysms via endovascular approach. Part 1 : electrochemical basis, technique, and experimental results. J Neurosurg 75:1-7, 1991

15. Halbach VV, Higashida RT, Hieshima GB, Hardin CW, Dowd CF, Barnwell SL: Transarterial occlusion of solitary intracerebral arteriovenous fistulas. AJNR Am J Neuroradiol 10:747-752, 1989

16. Houdart E, Gobin YP, Casasco A, Aymard A, Herbreteau D, Merland JJ: A proposed angiographic classification of intracranial arteriovenous fistulae and malformations. Neuroradiology 35:381-385, 1993

17. Hung PC, Wang HS: Successful endovascular treatment of cerebral arteriovenous fistula. Pediatr Neurol 27:300-302, 2002

18. Kerber C: Use of balloon catheters in the treatment of cranial arterial abnormalities. Stroke 11:210-216, 1980

19. Kerber CW: Balloon catheter with a calibrated leak. Radiology 120:547-550, 1976

20. Lawdahl RB, Routh WD, Vitek JJ, McDowell HA, Gross GM, Keller FS: Chronic arteriovenous fistulas masquerading as arteriovenous malformations: diagnostic considerations and therapeutic implications. Radiology 170:1011-1015, 1989

21. Lownie SP, Duckwiler GR, Fox AJ, Drake CG: Endovascular therapy of nongalenic cerebral arteriovenous fistulas, in Viñuela F, Halbach VV, Dion JE (eds): Interventional Neuroradiology: Endovascular Therapy of the Central Nervous System. New York: Raven Press, Ltd, 1992, pp 87-106

22. Luessenhop AJ, Presper JH: Surgical embolization of cerebral arteriovenous malformations through internal carotid and vertebral arteries. Long-term results. J Neurosurg 42:443-451, 1975

23. Luessenhop AJ, Spence WT: Artificial embolization of cerebral arteries. Report of use in a case of arteriovenous malformation. JAMA 172:1153-1155, 1960

24. McCormick WF. The pathology of vascular ("arteriovenous") malformations. J Neurosurg 24:807-816, 1966
25. Meyer FB, Grady RE, Abel MD, Nichols DA, Caminha SS, Robb RA, et al: Resection of a large temporooccipital parenchymal arteriovenous fistula by using deep hypothermic circulatory bypass. Case report. J Neurosurg 87:934-939, 1997

26. Noran HH. Intracranial vascular tumors and malformations. Arch Path 39:393-416, 1945

27. Oda M, Takahashi JA, Hashimoto N, Koyama T: Rendu-OslerWeber disease with a giant intracerebral varix secondary to a high-flow pial AVF: case report. Surg Neurol 61:353-356, 2004

28. Pevsner PH: Microballoon catheter for superselective angiography and therapeutic occlusion. AJR Am J Roentgenol 128: 225-230, 1977

29. Pevsner PH, Doppman JL: Therapeutic embolization with a microballoon catheter system. AJNR Am J Neuroradiol 1: 171-180, 1980

30. Reck SD, Zacks DN, Eibschitz-Tsimhoni M: Retinal and intracranial arteriovenous malformations: Wyburn-Mason syndrome. J Neuroophthalmol 25:205-208, 2005

31. Santosh C, Teasdale E, Molyneux A: Spontaneous closure of an intracranial middle cerebral arteriovenous fistula. Neuroradiology 33:65-66, 1991

32. Serbinenko FA: Balloon catheterization and occlusion of major cerebral vessels. J Neurosurg 41:125-145, 1974

33. Spetzler RF, Martin NA, Carter LP, Flom RA, Raudzens PA, Wilkinson E: Surgical management of large AVMs by staged embolization and operative excision. J Neurosurg 67:17-28, 1987

34. Spetzler RF, Wilson CB, Weinstein P, Mehdorn M, Townsend J, Telles D: Normal perfusion pressure breakthrough theory. Clin Neurosurg 25:651-672, 1978

35. Tomlinson FH, Piepgras DG, Nichols DA, Rufenacht DA, Kaste SC: Remote congenital cerebral arteriovenous fistulae associated with aortic coarctation. Case report. J Neurosurg 76:137-142, 1992

36. Tomlinson FH, Rufenacht DA, Sundt TM Jr, Nichols DA, Fode NC: Arteriovenous fistulas of the brain and the spinal cord. J Neurosurg 79:16-27, 1993

37. Vassilyadi M, Jones BV, Ball WS Jr: Identification of an arteriovenous fistula in a child. Case report and review of the literature. Childs Nerv Syst 17:685-688, 2001

38. Viñuela F, Drake CG, Fox AJ, Pelz DM: Giant intracranial varices secondary to high-flow arteriovenous fistulae. J Neurosurg 66:198-203, 1987

39. Viñuela F, Fox AJ, Debrun G, Pelz D: Preembolization superselective angiography: role in the treatment of brain arteriovenous malformations with isobutyl-2 cyanoacrylate. AJNR Am J Neuroradiol 5:765-769, 1984

40. Viñuela F, Fox AJ, Kan S, Drake CG: Balloon occlusion of a spontaneous fistula of the posterior inferior cerebellar artery. Case report. J Neurosurg 58:287-290, 1983

41. Viñuela FV, Debrun GM, Fox AJ, Girvin JP, Peerless SJ: Dominant-hemisphere arteriovenous malformations: therapeutic embolization with isobutyl-2-cyanoacrylate. AJNR Am J Neuroradiol 4:959-966, 1983

42. Willinsky RA, Lasjaunias P, Terbrugge K, Burrows P: Multiple cerebral arteriovenous malformations (AVMs). Review of our experience from 203 patients with cerebral vascular lesions. Neuroradiology 32:207-210, 1990

43. Wolpert SM, Stein BM: Catheter embolization of intracranial arteriovenous malformations as an aid to surgical excision. Neuroradiology 10:73-85, 1975

Manuscript received April 14, 2006.

Accepted in final form May 16, 2006.

No grants or other sources of financial support were received by any of the authors in conjunction with the generation of this manuscript.

Address reprint requests to: Kristen Upchurch, M.D., Division of Neurosurgery, David Geffen School of Medicine, University of California Los Angeles, Box 957039 NPI, Los Angeles, California 90095-7039. email: kupchurch@mednet.ucla.edu. 